European Polymer Journal

Volume 103, June 2018, Pages 228-237

https://doi.org/10.1016/j.eurpolymj.2018.04.016

\title{
MELT STABILIZATION OF PE WITH NATURAL ANTIOXIDANTS: COMPARISON OF RUTIN AND QUERCETIN
}

\begin{abstract}
Balázs Kirschweng ${ }^{1,2}$, Dániel Mirkó Tilinger ${ }^{1,2}$, Bence Hégely ${ }^{3}$, Gyula Samu ${ }^{3}$, Dóra Tátraaljai $^{1,2}$, Enikő Földes ${ }^{1,2}$, Béla Pukánszky ${ }^{1,2, *}$
\end{abstract}

${ }^{1}$ Laboratory of Plastics and Rubber Technology, Department of Physical Chemistry and Materials Science, Budapest University of Technology and Economics, H-1521 Budapest, P.O. Box 91, Hungary

${ }^{2}$ Institute of Materials and Environmental Chemistry, Research Centre for Natural Sciences, Hungarian Academy of Sciences, H-1519 Budapest, P.O. Box 286, Hungary

${ }^{3}$ MTA-BME Lendület Quantum Chemistry Research Group, Department of Physical Chemistry and Materials Science, Budapest University of Technology and Economics, P.O. Box 91, H-1521 Budapest, Hungary

*Corresponding author: Laboratory of Plastics and Rubber Technology, Department of Physical Chemistry and Materials Science, Budapest University of Technology and Economics, H-1521 Budapest, P.O. Box 91, Hungary. Tel: 36-1-463-2015, Fax: 36-1463-3474, E-mail: bpukanszky@mail.bme.hu 


\section{ABSTRACT}

The stabilization effect of a flavonoid type natural antioxidant, rutin, was compared to that of quercetin in polyethylene. Additive concentrations changed between 0 and 500 ppm in several steps and also 1000 ppm Sandostab PEPQ phosphorus secondary stabilizer was added to each compound. Stabilization efficiency was determined by changes in vinyl group content, melt flow rate, oxygen induction time, color and the consumption of the secondary antioxidant during multiple extrusions. The results showed that rutin is as efficient melt stabilizer as quercetin used as reference. On the other hand, rutin has a deteriorating effect on the stability of the polymer at small concentrations and partially decomposes during processing. The comparison of bond dissociation enthalpies indicated that the substitution of the hydroxyl group in the $\mathrm{C}$ ring of quercetin by saccharide moieties increases their value, but the small increase does not influence the efficiency of the stabilizer. FTIR and DSC measurements indicated the interaction of the natural antioxidant and the phosphonite secondary stabilizer, and the development of interactions was confirmed by molecular modeling. Mainly hydrogen bonds and aromatic, $\pi$ electron interactions develop between the hydroxyl groups in ring A and the POC group of the phosphonite, as well as between the aromatic rings of PEPQ and the flavonoids, but they do not influence the stabilization efficiency of the antioxidants.

KEYWORDS: polyethylene, processing stabilization, long chain branching, natural antioxidants, rutin

\section{INTRODUCTION}

Plastics are exposed to heat, shear and oxygen during their processing and to various effects during their application that may result in degradation [1]. In order to prevent 
changes in their chemical structure and properties, they contain heat and/or light stabilizers practically always. Polyethylene is routinely protected against degradation during processing with the combination of a synthetic phenolic antioxidant and a secondary, processing stabilizer, usually a phosphorous compound. This simple stabilization package proved to be very efficient and cost effective thus very few new stabilizers appeared on the market in the last few decades. However, for various reasons, the interest turned towards natural antioxidants recently. The general concern of the politicians and the public about sustainable economy is one of the driving forces, while doubts about the possible environmental and health hazard [2] of the degradation products of phenolic antioxidants used routinely also may play a role in this increased interest. Consequently, the number of publications about the possible use of natural antioxidants for the stabilization of polymers increases continuously.

A considerable number of natural compounds proved to be beneficial for the human health because of their antioxidant, anti-inflammatory, antiviral or other effects and many of them are being used for therapy for a very long time. Natural antioxidants are used in increasing quantities also in food products $[3,4]$. Attempts have been made to apply various natural compounds for the stabilization of polymers, and specifically polyolefins as well. Vitamin E is a very efficient stabilizer [5-8] and it is presently used as antioxidant in ultrahigh molecular weight polyethylene implants [9-11]. Because of its polyaromatic structure and the number of phenolic hydroxyl groups in it, lignin has a stabilization effect in polymers, which was proved both in polyethylene and polypropylene [12-14]. Several attempts were reported in the literature to use flavonoids for the stabilization of polyolefins. Quercetin, a natural antioxidant, was explored as possible stabilizer both in food [15] and in polymers [16,17] and most of the results obtained confirmed its efficiency indeed. Dihydromyricetin, another flavonoid was also studied as stabilizer in both PE and PP and 
proved more efficient than the commercial stabilizers used as reference $[18,19]$.

Among other groups, we also carried out experiments to explore the effect and efficiency of several natural compounds as stabilizer in PE. The antioxidant effect of curcumin [20,21], quercetin [22], dihydromyricetin [23] and silymarin [24] was studied in a Phillips type polyethylene in the presence of a phosphorous secondary stabilizer. Three of them are very efficient, their stabilization efficiency exceed that of the synthetic phenolic antioxidant used in the largest quantity in industrial practice. The stabilizers protected the polymer against degradation during processing already at the concentration of $50 \mathrm{ppm}$ and provided sufficient residual stability at $250 \mathrm{ppm}$. Silymarin was less efficient, because of its slightly different chemical structure [24]. In this work we study the possible stabilization effect of rutin, [2-(3,4-dihydroxyphenyl)-5,7-dihydroxy-3-\{[(2S,3R,4S, 5S,6R)-3,4,5trihydroxy-6-(\{[(2R,3R,4R,5R,6S)-3,4,5-tri-hydroxy-6-methyloxan-2-yl]oxy $\}$ methyl)oxan2-yl]oxy\}-4H-chromen-4-one], a natural antioxidant which belongs to the family of flavonoid glycosides. The compound is the glycoside of quercetin formed with the rutinose disaccharide. It can be found in numerous fruits, citruses, apple, buckwheat and Japanese acacia. It obtained its name from the flower Ruta graveolens that contains it in large quantities similarly to other yellow flowers [25]. Rutin has several beneficial effects on the human body; it protects the heart and the arteries, as well as the neural system, since as an antioxidant it neutralizes free radicals [26]. Research is going on to use it as an antidepressant [27] or to treat Alzheimer disease [28] and stroke [29] with it.

Most of the flavonoid type natural antioxidants investigated in the previous projects proved to be very efficient processing stabilizers for PE, but they all had some drawbacks like high melting temperature, limited solubility in the polymer and strong color. Consequently, the primary goal of this work was to try another member of the flavonoid family, rutin, as antioxidant in PE. Similarly to previous works [20-24], rutin was used in 
combination with a phosphorous secondary stabilizer to comply with industrial practice. The effect of the new antioxidant was compared to that of quercetin used as reference compound. Besides the effect of rutin on the processing stability of polyethylene, we paid more attention to mechanistic aspects and to the possible interaction of the primary and the secondary antioxidant, since previous results indicated that the two types of compounds, i.e. the flavonoids and the phosphonite, interact with each other and the developing interactions might affect their efficiency.

\section{EXPERIMENTAL}

\subsection{Materials}

The polymer used in the experiments was the Tipelin FS 471 grade ethylene/1hexene copolymer (melt flow rate: $0.3 \mathrm{~g} / 10 \mathrm{~min}$ at $190{ }^{\circ} \mathrm{C}, 2.16 \mathrm{~kg}$; nominal density: 0.947 $\mathrm{g} / \mathrm{cm}^{3}$ ) polymerized with a Phillips catalyst (PE). The number average molecular weight of the polymer is $15.4 \mathrm{~kg} / \mathrm{mol}$, its polydispersity 7.6 and it contains 1.81 comonomer/1000 C. The additive free polymer powder was provided by MOL Group Ltd., Hungary. Both stabilizers, i.e. rutin and quercetin, were purchased from Sigma-Aldrich with 95 and $94 \%$ purity, respectively. The antioxidants were added to the polymer in various amounts, in 5 , $10,25,50,100,250$ and $500 \mathrm{ppm}$, to study the effect of additive content on stability. Each compound contained also $1000 \mathrm{ppm}$ Sandostab PEPQ (PEPQ, Clariant) phosphonite secondary stabilizer.

\subsection{Sample preparation}

The polymer and the additives were homogenized in a high-speed mixer (Henschel FM/A10) at a rate of $500 \mathrm{rpm}$ for $10 \mathrm{~min}$. The necessary amount of quercetin was dissolved in $200 \mathrm{~mL}$ acetone and the solution was added to the PE powder in the mixer. The resulting 
powder was dried overnight to remove acetone. Rutin was added to the polymer together with PEPQ directly and homogenized in the high-speed mixer under the same conditions as described above. The dry blend was processed and pelletized in six consecutive extrusion steps at $50 \mathrm{~min}^{-1}$ and barrel temperatures of 180, 220, 260 and $260{ }^{\circ} \mathrm{C}$ under normal laboratory conditions using a Rheomex S 3/4" type single screw extruder attached to a Haake Rheocord EU 10V driving unit. Samples were taken after each extrusion step. For further studies, films of about $100 \mu \mathrm{m}$ thickness were compression molded at $190{ }^{\circ} \mathrm{C}$ and $5 \mathrm{~min}$ using a Fontijne SRA 100 machine. Blends of the two stabilizers, i.e. the natural antioxidant and PEPQ, were prepared by mixing the components in various amounts in 2-propanol to study their interactions. The solvent was evaporated in a Büchi Rotavapor R-210 vacuum assisted rotary distillation apparatus in about 1 hour at $40{ }^{\circ} \mathrm{C}$, then the mixtures were dried further overnight at $100{ }^{\circ} \mathrm{C}, 200$ mbar in a vacuum oven.

\subsection{Characterization}

The melt flow rate (MFR) of the polymer was determined according to the ASTM D 1238-79 standard at $190{ }^{\circ} \mathrm{C}$ with $2.16 \mathrm{~kg}$ load using a Göttfert MPS-D MFR tester. Residual thermo-oxidative stability was characterized by the oxidation induction time (OIT) measured at $200{ }^{\circ} \mathrm{C}$ in oxygen atmosphere with constant, $20 \mathrm{~mL} / \mathrm{min}$ flow rate in open aluminum pans using a Perkin Elmer DSC-7 apparatus. The concentration of the unsaturated functional groups of polyethylene were determined by FTIR spectroscopy on the $100 \mu \mathrm{m}$ thick compression molded films in transmission mode using a Tensor 27 (Bruker) spectrophotometer. Five spectra were recorded on each sample between 4000 and $400 \mathrm{~cm}^{-1}$ wavelengths at $2 \mathrm{~cm}^{-1}$ resolution and 16 scans. The concentration of vinyl groups were calculated from the absorption at $908 \mathrm{~cm}^{-1}$. FTIR spectroscopy was used also for the determination of residual PEPQ content based on the absorption of the P(III)-O-C groups at 
$850 \mathrm{~cm}^{-1}$. The color of the samples was described by the yellowness index (YI) and the optical L* parameter determined with a Hunterlab Colourquest 45/0 apparatus. The thermal behavior of rutin, that of its blends with PEPQ, and component interactions were studied by differential scanning calorimetry (DSC). The measurements were carried out in nitrogen atmosphere with constant, $20 \mathrm{~mL} / \mathrm{min}$ flow rate in open aluminum pans, at a heating rate of $10{ }^{\circ} \mathrm{C} / \mathrm{min}$ from 0 to $350{ }^{\circ} \mathrm{C}$ using a Perkin Elmer Diamond DSC-IC apparatus. The thermal stability of the two natural antioxidants was checked by thermogravimetry using a Perkin Elmer STA-6000 apparatus. Samples were heated from $30{ }^{\circ} \mathrm{C}$ up to $260{ }^{\circ} \mathrm{C}$ at $20{ }^{\circ} \mathrm{C} / \mathrm{min}$ rate and then held there for $15 \mathrm{~min}$. The measurements were carried out in oxygen atmosphere with constant, $20 \mathrm{~mL} / \mathrm{min}$, flow rate. The possible interactions of the components were estimated also by molecular modeling using the density functional theory (DFT). The details of the calculations are given in the respective section (section 3.4). In figures, rutin is abbreviated as $\mathrm{R}$, while quercetin as $\mathrm{Q}$ in order to increase clarity and help understanding.

\section{RESULTS AND DISCUSSION}

The results are reported in several sections. First, the characteristics of the two antioxidants are compared and based on their structure an attempt is made to predict their performance. The stabilization efficiency of the two compounds is presented in the next section. Mechanistic aspects and additive interactions are considered in the following two sections, while unresolved issues as well as consequences for practice are discussed in the final section of the paper.

\subsection{Antioxidant characteristics}

Rutin is a flavonoid type antioxidant with very similar structure to quercetin. The 
latter is a very efficient antioxidant not only in nature, but also in polyethylene under processing conditions [22], thus we expected rutin to perform similarly well. Besides its strong stabilization effect quercetin has several drawbacks, like the high melting temperature resulting in difficulties during homogenization, its small solubility in the polymer and discoloration effect even at small concentrations [22].

The characteristics of the two natural antioxidants are compared to each other in Table 1. Their chemical structure is quite similar, the only difference is the two saccharide rings attached through the $\mathrm{OH}$ group in position 3 of ring $\mathrm{C}$. The number of phenolic $\mathrm{OH}$ groups is the same and the double bond is present in ring $\mathrm{C}$ as well. Consequently, stabilizing efficiency should be approximately the same, although also the $\mathrm{OH}$ group in ring $\mathrm{C}$ was shown to take part in stabilization reactions [30,31]. The effect of the attachment of the rutinose disaccharide is difficult to predict, it may change the bond dissociation energy of the phenolic $\mathrm{OH}$ groups (see Section 3.3) or can interact with these latter thus decreasing their efficiency.

If we consider the drawbacks of quercetin listed above, the melting temperature of rutin is much smaller than that of quercetin, which is a clear advantage. The lower melting point facilitated homogenization; rutin was added directly to the polymer powder without the use of a solvent-based procedure. The color of the two additives comes from the conjugation of the double bond in ring $\mathrm{C}$ mainly with the free electrons on the oxygen atoms of ring $\mathrm{C}$ and the aromatic $\pi$ electrons in ring A. Accordingly, strong discoloration effect is expected also from rutin in spite of the fact that the color of the two antioxidants differ somewhat. Unfortunately, not much difference is expected in the solubility of the two compounds either, the large number of polar $\mathrm{OH}$ groups in the disaccharide moiety does not facilitate the dissolution of the rutin molecule in PE. Based on Table 1, similar efficiency, but small solubility and strong discoloration is expected when rutin is used as stabilizer in 
polyethylene.

Table 1 Comparison of the characteristics of the two antioxidants used in the study

\begin{tabular}{|c|c|c|}
\hline Characteristics & Quercetin & Rutin \\
\hline $\mathrm{M}_{\mathrm{n}}(\mathrm{g} / \mathrm{mol})$ & 302.2 & 610.5 \\
\hline Melting point $\left({ }^{\circ} \mathrm{C}\right)$ & 316 & 167 \\
\hline \multicolumn{3}{|l|}{ Color } \\
\hline Structure & & \\
\hline Structural differences & - hydroxyl in C ring & $\begin{array}{l}- \text { no hydroxyl in } \mathrm{C} \text { ring } \\
- \text { two sugar rings attached }\end{array}$ \\
\hline Phenolic OH groups & 4 & 4 \\
\hline
\end{tabular}

\subsection{Stabilization efficiency}

Phillips type polyethylenes have a double bond at one end of each chain thus its dominating degradation reaction during processing is the formation of long chain branches [32]. The viscosity of the polymer increases as a result and its MFR decreases at the same time. The vinyl group content of the polymer is plotted as a function of the number of processing steps in Fig. 1. Only a few, selected compositions are shown to avoid confusion 
and facilitate the viewing of the results. Vinyl content decreases with increasing processing history as expected and both stabilizers hinder the reactions resulting in long chain branching. Quite surprisingly, the vinyl group content of the polymer is smaller at 5 but especially at $10 \mathrm{ppm}$ rutin content than that of the neat polymer containing only the secondary antioxidant. Vinyl content increases at all concentrations in the presence of quercetin compared to the reference compound. However, such differences are not observed at large additive contents; the concentration of vinyl groups is practically the same in the presence of both natural antioxidants. The negative effect of rutin at small additive contents needs further study and considerations.

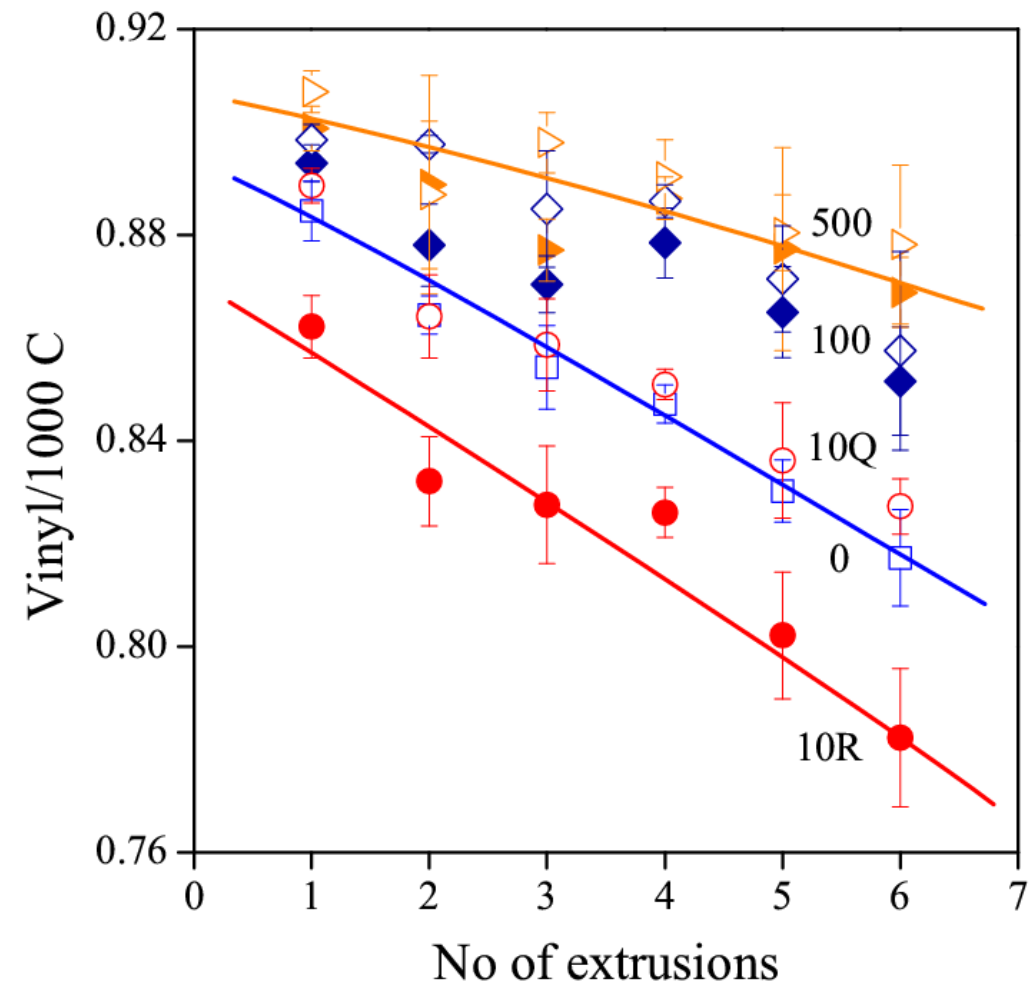

Fig. 1 Effect of the number of extrusion steps and additive concentration on the vinyl group content of PE. Symbols: $(\square)$ neat, $(\bigcirc, \bigcirc) 10$ ppm, $(\diamond, \diamond) 100$ ppm, (, 500 ppm additive; empty: quercetin, full: rutin. 
The influence of the additives was presented as a function of processing history in Fig. 1. However, the molecular weight of the two antioxidants differs considerably, thus the molar concentration of the active phenolic groups is also different. In order to check the effect of the two compounds at equal molar concentrations, the number of vinyl groups is plotted against antioxidant content in Fig. 2. Apart from small concentrations, the effect of the two natural antioxidants is very similar confirming the conclusions drawn above. At very small additive contents, rutin accelerates the consumption of the double bonds, but it protects the polymer against degradation similarly to quercetin at large concentrations.

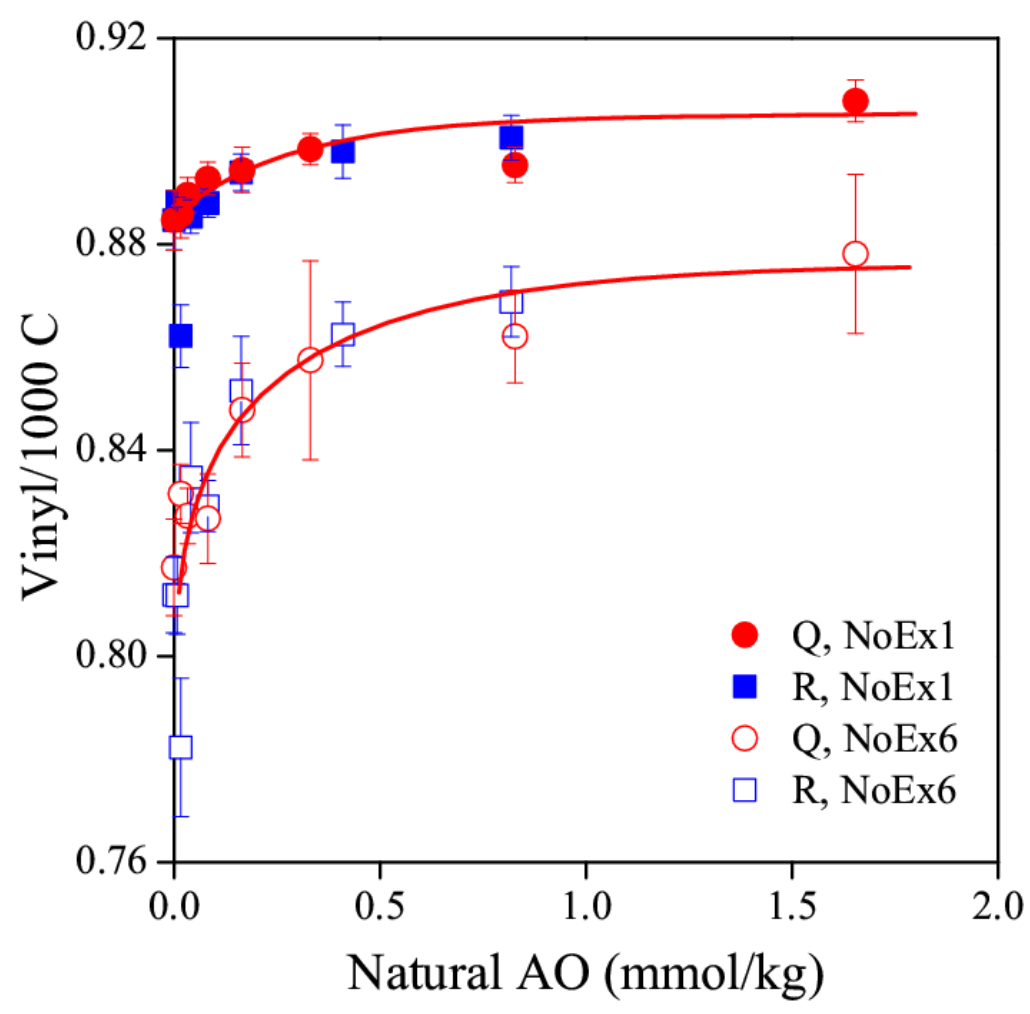

Fig. 2 Dependence of the number of vinyl groups of PE on the concentration of the natural antioxidant. Symbols: (O) Q, NoEx1, (ם) R, NoEx1, (O) Q, NoEx6, ( $\square)$ NoEx6. 
Earlier studies have shown that the presence of the secondary antioxidants, the phosphonite in our case, is essential for the protection of the polymer. The residual amount of the phosphonite antioxidant is plotted against the number of extrusions in Fig. 3. At 10 ppm, rutin accelerates the consumption of the secondary antioxidant and it seems to be inferior even at $100 \mathrm{ppm}$ than quercetin. On the other hand, the effect of the two natural antioxidants is very similar at the largest additive content, at $500 \mathrm{ppm}$. Apparently, rutin takes part in a reaction or reactions, which results in the consumption of PEPQ and the insufficient amount of secondary antioxidant leads to the faster consumption of vinyl groups. This latter usually indicates the formation of long chain branches and the increase of viscosity.

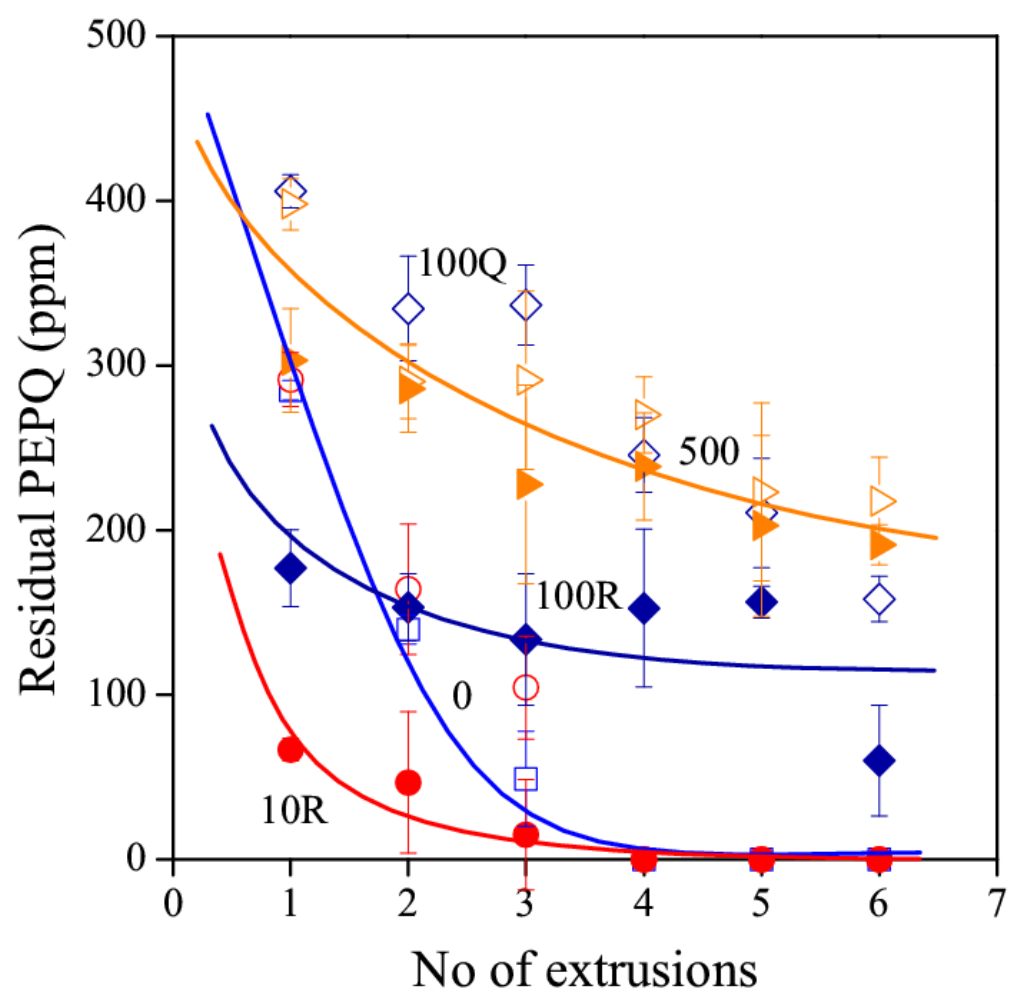

Fig. 3 Influence of processing history (NoEx) and additive content on the amount of residual secondary stabilizer (PEPQ) remaining in the polymer after extrusion. 
Symbols: $(\square)$ neat, $(\bigcirc, \bigcirc) 10$ ppm, $(\diamond, \diamond) 100$ ppm, $(\triangleright, \triangleright) 500$ ppm additive; empty: quercetin, full: rutin.

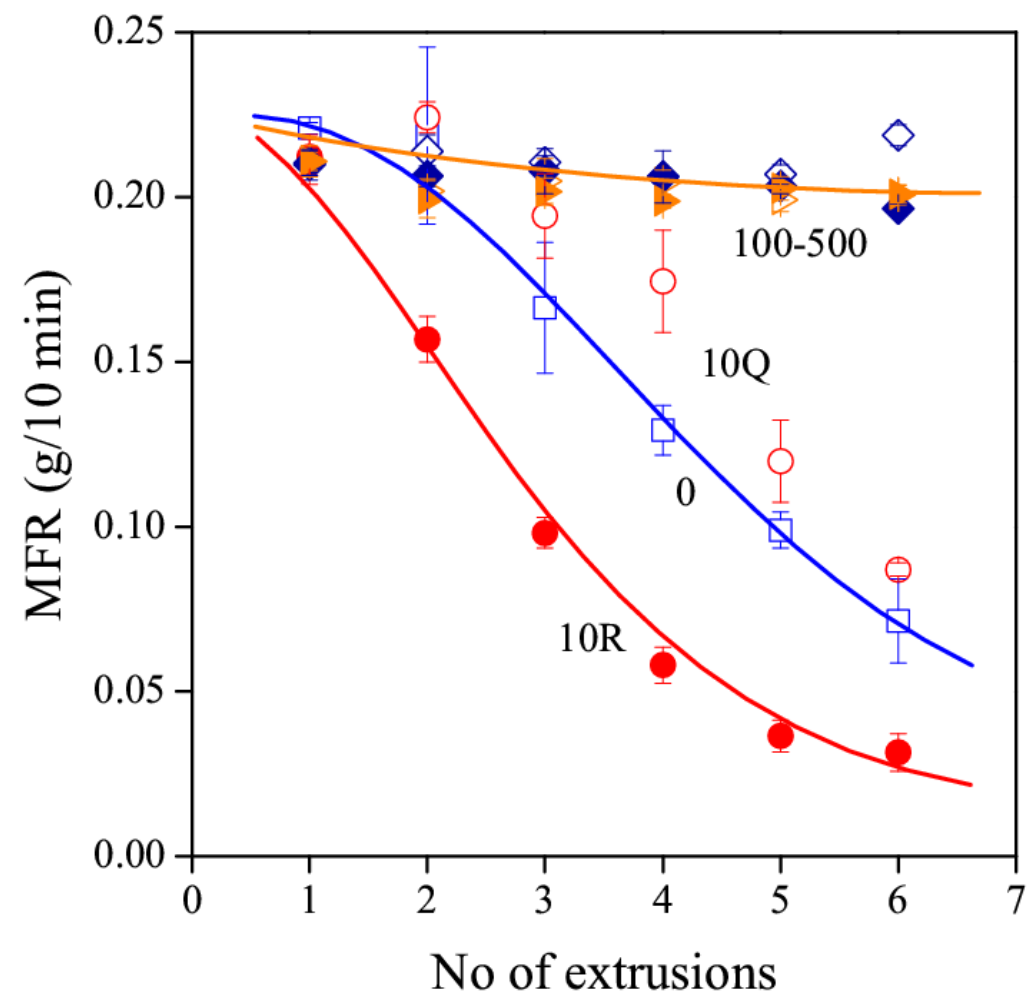

Fig. 4 Effect of the number of extrusions and the amount of natural antioxidant added on the viscosity (MFR) of PE. Symbols: $(\square)$ neat, $(\bigcirc, \bigcirc) 10$ ppm, $(\diamond, \diamond) 100$ ppm, $(\triangleright, \triangleright) 500$ ppm additive; empty: quercetin, full: rutin.

The MFR of the polymer is plotted against the number of extrusion steps in Fig. 4. The differences predicted above are clearly seen in the figure. Compared to the neat polymer, MFR decreases considerably at the rutin content of $10 \mathrm{ppm}$, while the presence of quercetin results in visible improvement in MFR already at this small concentration. The differences are obviously related to the consumption of the secondary antioxidant and the reaction of the vinyl groups as described above. On the other hand, the effect of the two 
additives is practically the same at large concentrations, above $100 \mathrm{ppm}$. In order to see the effect of additive content better and account for the dissimilar molecular weight of the two additives, MFR is plotted against additive content in molar concentrations in Fig. 5. Considerable improvement is seen in viscosity after the sixth extrusion with increasing antioxidant concentration, while a slight decrease in efficiency after the first processing step. This latter was explained with the interaction of the two kinds of antioxidants before $[22,24]$. However, the results clearly prove that apart from small concentrations, both natural antioxidants protect the polymer against degradation during processing equally efficiently.

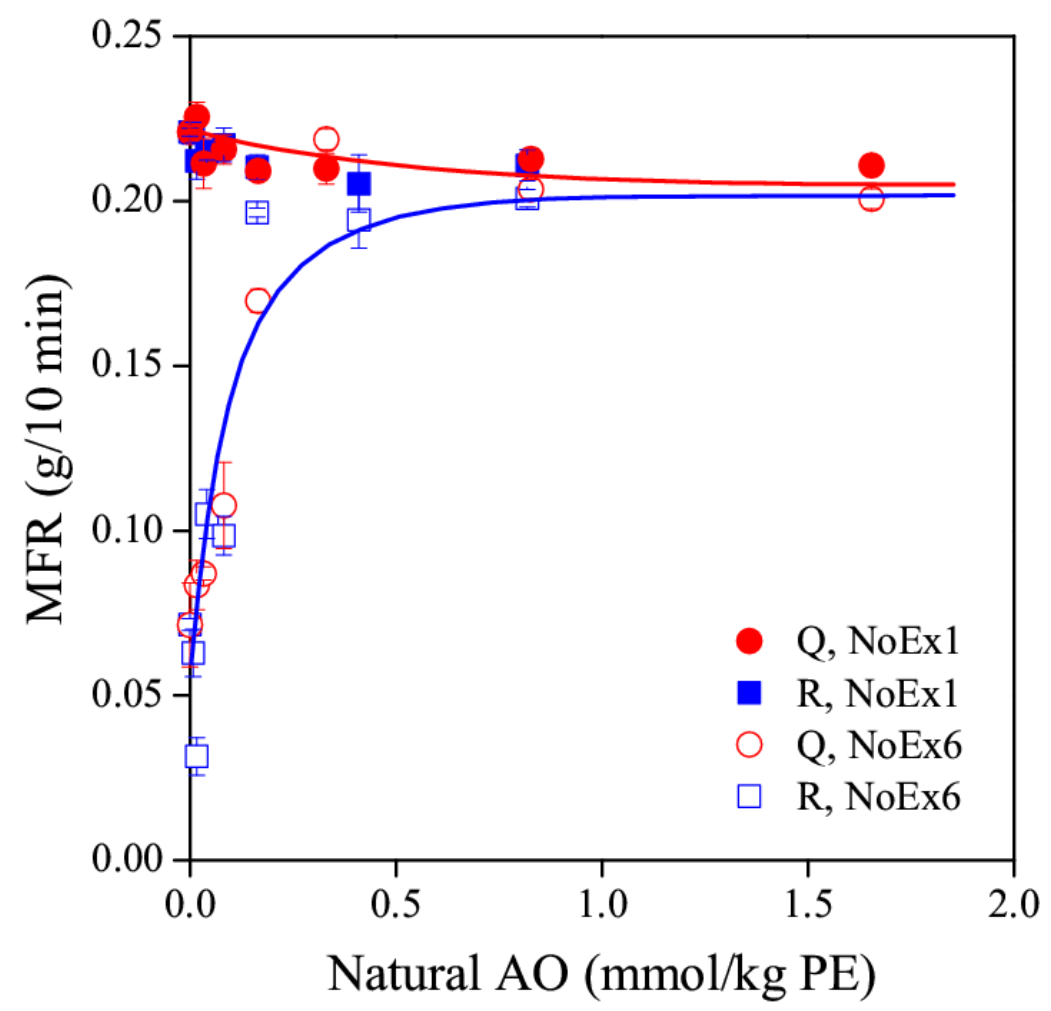

Fig. 5 Dependence of MFR on the concentration of natural antioxidant after the $1^{\text {st }}$ and $6^{\text {th }}$ extrusions. Symbols: (O) Q, NoEx1, (ם) R, NoEx1, (O) Q, NoEx6, ( $\square)$ NoEx6. 


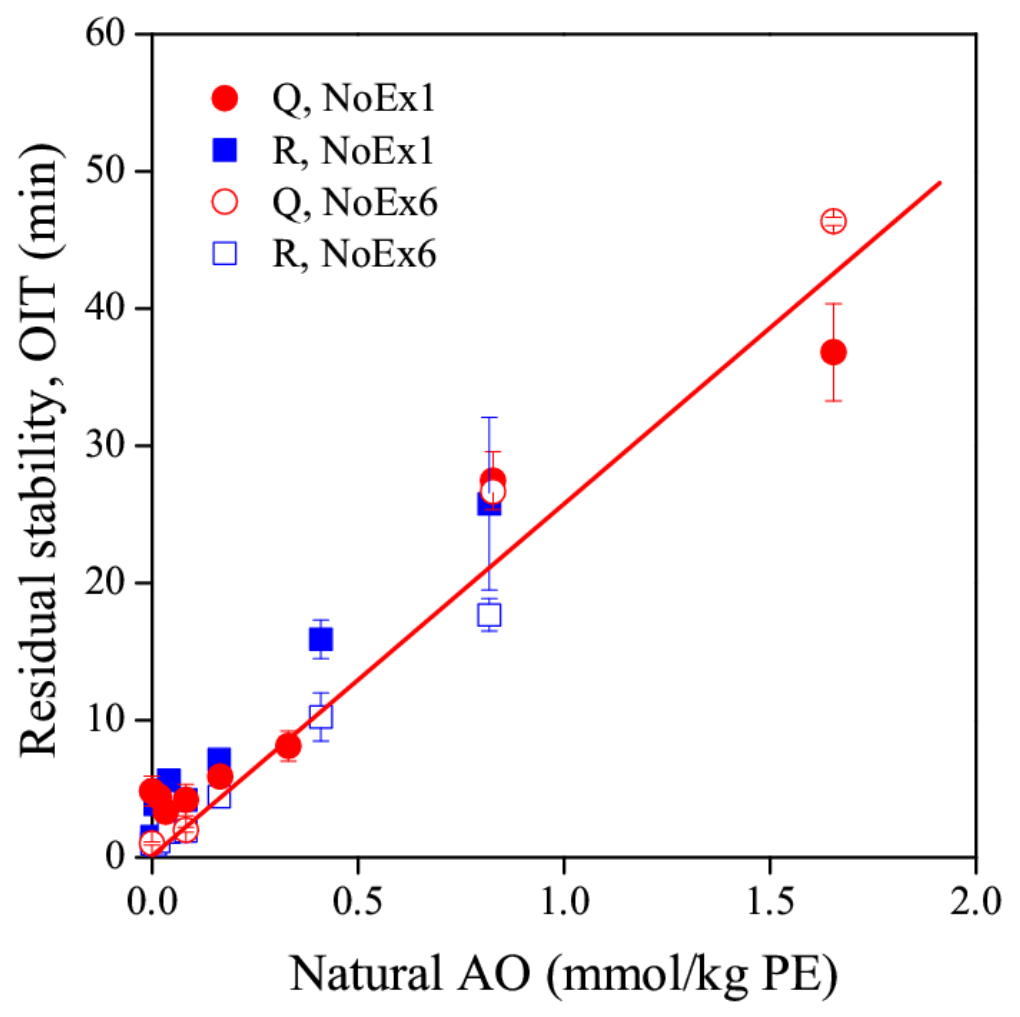

Fig. 6 Linear dependence of the residual stability of PE on the concentration of the natural antioxidant. Similarity of quercetin and rutin. Symbols: $(\mathbf{O})$ Q, NoEx1, ( $)$ R, NoEx1, (O) Q, NoEx6, ( $\square)$ NoEx6.

The residual stability of the polymer is very important in certain, long-term applications, e.g. for pipes. Residual stability, characterized by the oxygen induction time (OIT), is plotted against the amount of the natural antioxidants on a molar basis in Fig. 6. Although the standard deviation of OIT results is usually quite large, the tendency is clear, residual stability increases practically linearly with the increasing amount of the natural phenolic antioxidants in accordance with some previous results [33-34]. Taking into account the uncertainty of the measurement, one cannot observe any difference in the efficiency of the two compounds. Considering all the results related to the stabilization effect of the two 
natural antioxidants studied, we must conclude that the replacement of the $\mathrm{OH}$ group in ring $\mathrm{C}$ with the disaccharide moiety does not influence the efficiency of the compound. On the other hand, some reaction or effect results in the deterioration of properties at small rutin contents, which needs further considerations.

\subsection{Mechanistic aspects}

Four mechanisms have been proposed in the literature for the stabilization reactions of phenolic antioxidants: single electron transfer (SET) [35-36], sequential proton loss electron transfer (SPLET) [37-38], radical adduct formation (RAF) [39] and hydrogen atom transfer (HAT) [40-41]. In polyethylene the last one is the most probable and accepted mechanism of stabilization [42-43]. The rate of hydrogen transfer depends on the dissociation enthalpy of the hydrogen atom from the phenolic hydroxyl groups and a relatively close correlation was found between the smallest bond dissociation enthalpies of the phenolic hydroxyl groups of selected natural antioxidants and the consumption of a secondary antioxidant (PEPQ) [44].

Bond dissociation enthalpies (BDE) can be determined by molecular modeling approaches. Cai et al. [45] calculated the bond dissociation enthalpies of the four phenolic hydroxyl groups of quercetin, hyperin containing one saccharide ring and rutin at the UB3LYPI6-311G level. The results are summarized in Table 2. According to the table, substitution at position 3 in ring $\mathrm{C}$ with increasing number of saccharide rings results in an increase of the BDE of all phenolic $\mathrm{OH}$ groups. The authors explained the increase with the increasing rotation of rings A and B relative to each other [45]. Similar results were obtained also by Renganathan et al. [46] showing the increase of BDE in rutin as the result of the substitution with the disaccharide ring. According to these calculations, the efficiency of rutin should be smaller than that of quercetin, but apart from small concentrations, this did 
not prove true. Obviously, in spite of the close correlation mentioned above [44], bond dissociation enthalpy is not the only factor determining the efficiency of the natural antioxidants studied.

Table 2 Effect of substitution on the reactivity of the active hydroxyl groups of natural antioxidants; comparison of quercetin, hyperin and rutin [45]

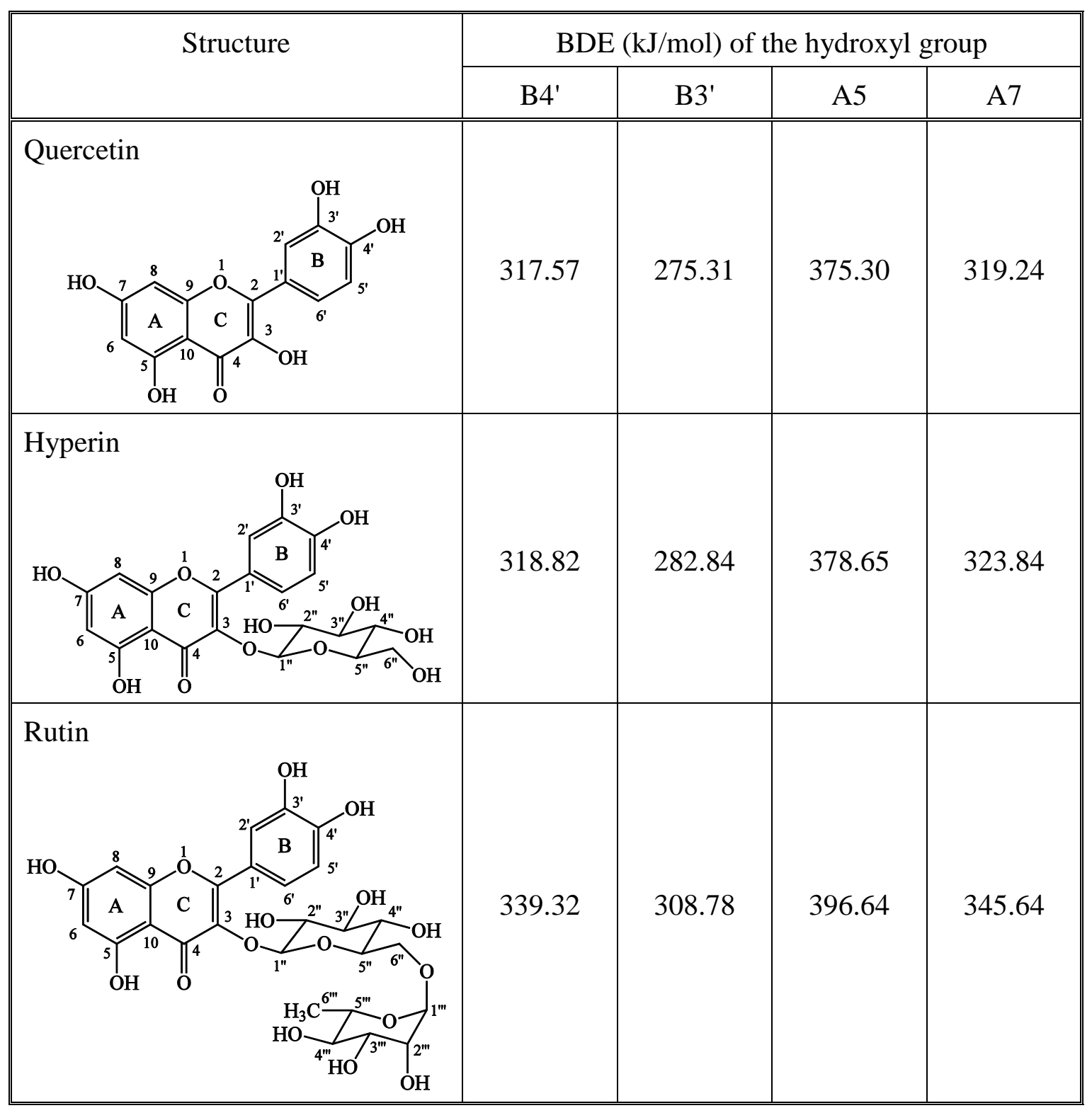


According to the HAT mechanism during its stabilization reaction quercetin first loses a hydrogen atom and then transforms into a quinoidal compound. Because of its hydroxyl group in ring C, quercetin can take a keto and an enol form [47-48]. Only the keto form occurs in rutin, because of the lack of hydroxyl in ring $\mathrm{C}$. The stabilization reaction of rutin is presented in Scheme 1. Reaction with the $\mathrm{DPPH}^{\bullet}$ radical showed that hydrogen abstraction occurs from the hydroxyls at the B3', B4' and C3 positions in quercetin, while at the B3' and B4' positions in rutin. The participation of the $\mathrm{C} 3$ hydroxyl in stabilization is supported by the fact that the number of $\mathrm{DPPH}^{\bullet}$ radicals scavenged by a quercetin molecule in $\mathrm{N}, \mathrm{N}$-dimethylformamide solution is 2.35 , compared to the value of 2.00 for rutin [49]. These results predict again smaller efficiency for rutin than for quercetin, which is not supported by the experimental results. Obviously, neither the smaller BDE values nor the lack of the $\mathrm{OH}$ group at the $\mathrm{C} 3$ position determines efficiency, since the reaction of the B3' and B4' hydroxyl groups is the decisive factor in stabilization. However, the calculations and the model experiments do not explain the smaller efficiency of rutin at small concentrations and the similar effect at large additive contents.

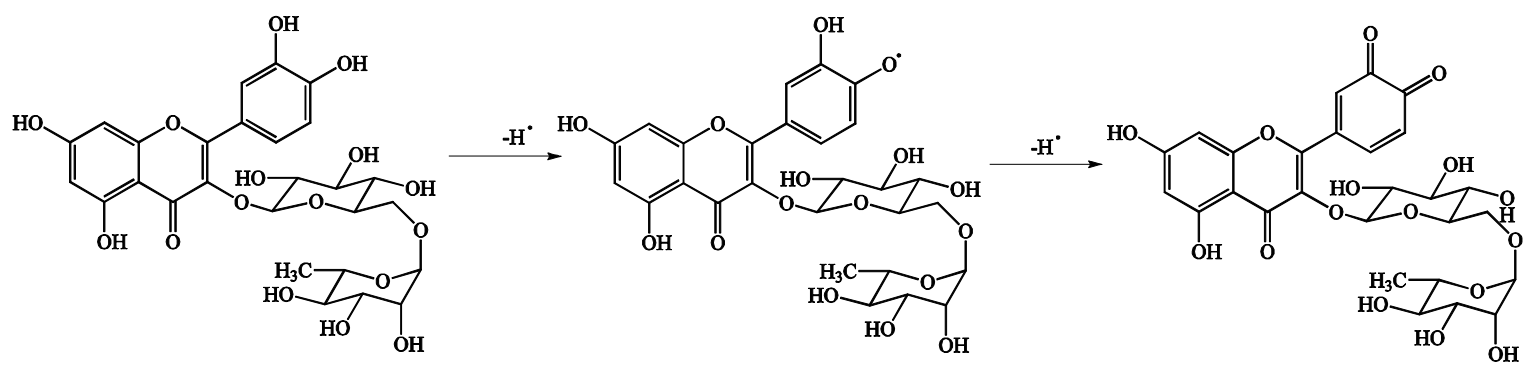

Scheme 1 Assumed HAT reaction mechanism of rutin.

\subsection{Interactions}

Some of the results obtained during the study of the stabilization efficiency of various natural antioxidants indicated that the primary and the secondary antioxidants interact with each other and that the interaction influences their efficiency [20,22]. The consumption of the phosphonite secondary stabilizer was quite different in the presence of 
the various natural antioxidants, which determined the efficiency of the entire package. The existence of interactions could be deduced from other phenomena as well. The melting traces of quercetin, PEPQ and the mixture of the two recorded by DSC are presented in Fig. 7. Quercetin has a sharp melting peak at around $320^{\circ} \mathrm{C}$, which becomes diffuse and shifts to lower temperatures in its $75 \mathrm{~mol} \%$ blend with PEPQ clearly indicating the interaction of the components. The effect is less clear in the case of rutin, because of its less regular structure. Interactions also might differ between rutin and PEPQ. The composition dependence of melting temperatures is presented in Fig. 8, showing strong changes in the melting temperature of quercetin, but hardly any effect for rutin. One might conclude that interactions are stronger between quercetin and PEPQ than for the rutin-PEPQ pair.

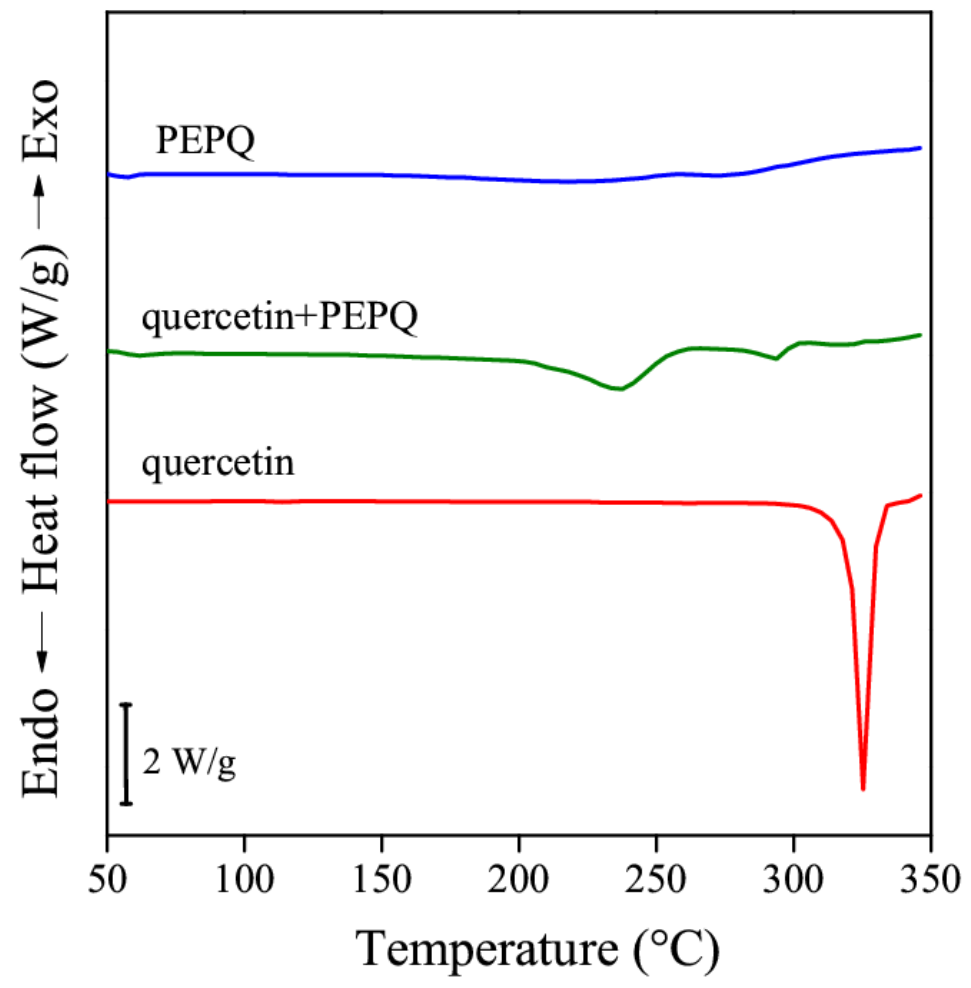

Fig. 7 DSC melting traces of PEPQ, quercetin and their mixture (75 mol\% quercetin and $25 \mathrm{~mol} \%$ PEPQ). Interaction of the additives. 


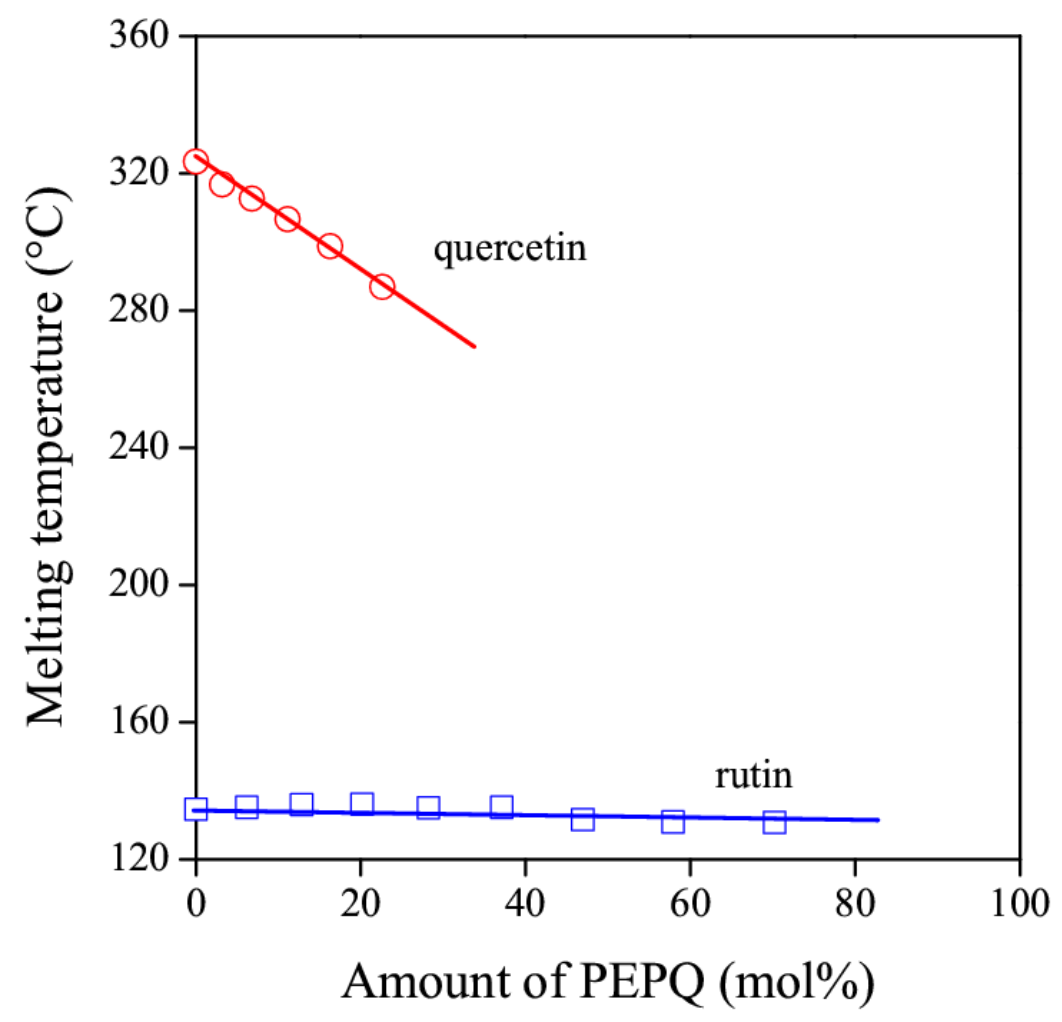

Fig. 8 Effect of composition on the melting temperature of the blend of PEPQ and natural antioxidants. Symbols: $(\bigcirc)$ quercetin, $(\square)$ rutin.

Changes in melting temperatures indicate the development of interactions, but do not tell anything about their character. The two components, PEPQ and the natural antioxidant, may form hydrogen bonds or enter into aromatic, $\pi$ electron interaction with each other. FTIR spectroscopy is an adequate tool to detect the formation of strong hydrogen bonds between two substances. A shift in the absorbance of the hydroxyl groups of the natural antioxidant or the change of the POC absorbance of PEPQ would be a clear indication of interactions. The dependence of the position of this latter vibration on the composition of natural antioxidant/PEPQ blends is presented in Fig. 9. Similarly, to melting temperatures, FTIR band shifts indicate stronger interactions between quercetin and PEPQ 
than between rutin and the secondary antioxidant.

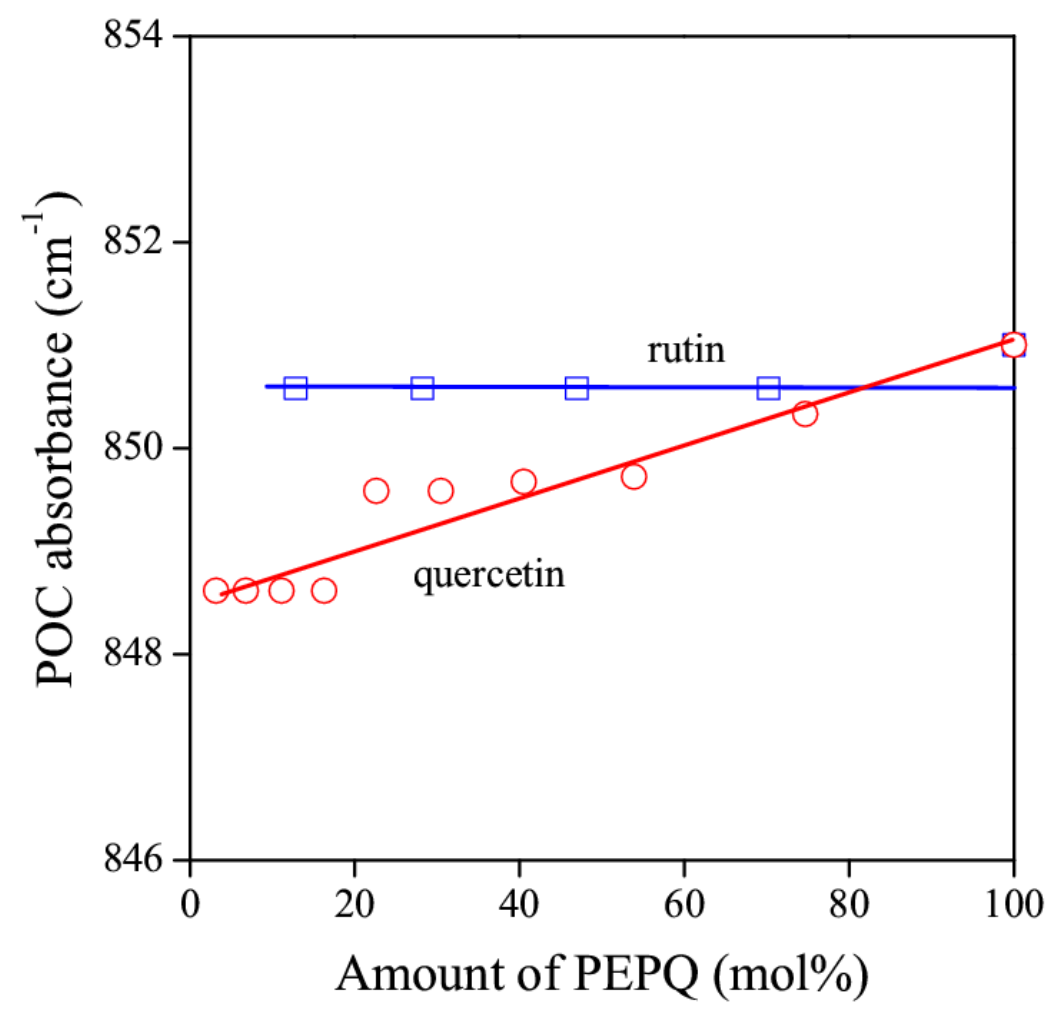

Fig. 9 Dependence of the position of the POC absorbance at $850 \mathrm{~cm}^{-1}$ wavenumber on the composition of PEPQ/natural antioxidant blends. Symbols: (O) quercetin, $(\square)$ rutin.

The reliability of these observations was checked by molecular modeling. We also hoped that the calculations reveal further details about the character of these interactions and identifies the participating groups. The association energies of the complexes were determined by the density functional theory (DFT) using the Perdew-Burke-Ernzerhof (PBE) functional [50]. The DFT calculations were performed with the MRCC program suite [51]. D3 corrections for dispersion were also carried out using the DFT-D3 software [5253]. Complex geometries were optimized in the following steps. First, conformers with the 
lowest energies for PEPQ, quercetin, and rutin were identified using the Merck molecular force field (MMF94) [54] by the MarvinSketch (ChemAxon) program [55]. These structures were then further optimized using the MOPAC2016 program suite [56] by applying the modified neglect of diatomic differential overlap (NDDO) based semi-empirical quantum chemistry method PM6 [57] with D3H4 [58] corrections for hydrogen bonding and dispersion. The termination criterion for the geometry optimization was $0.042 \mathrm{~kJ} / \mathrm{mol} / \AA$ for the gradient norm. Starting geometries for the complexes were produced using the Maestro 11 program [59]. The ligands were placed over and under the (2,4-di-tert-butylphenyl) groups at one side of the PEPQ molecule, and also over and under its biphenyl groups. In each of these four placements four starting geometries were produced which were rotated by $90^{\circ}$ with respect to each other, resulting in 16 initial geometries for both the quercetin and rutin complexes. These structures were then also optimized by PM6-D3H4. The DFT calculations were converged with the $6-31 \mathrm{G}^{*}$ basis set, and first-order corrections to the energy were evaluated with the aug'-cc-pVDZ basis set. First, the association energies were calculated as the difference between the energy of the complex and the sum of the energies of the individual molecules. These energies were then corrected for basis set superposition error applying counterpoise correction [60]. Finally probabilities were rendered to each complex structures based on the Boltzmann distribution of their corrected association energies. 


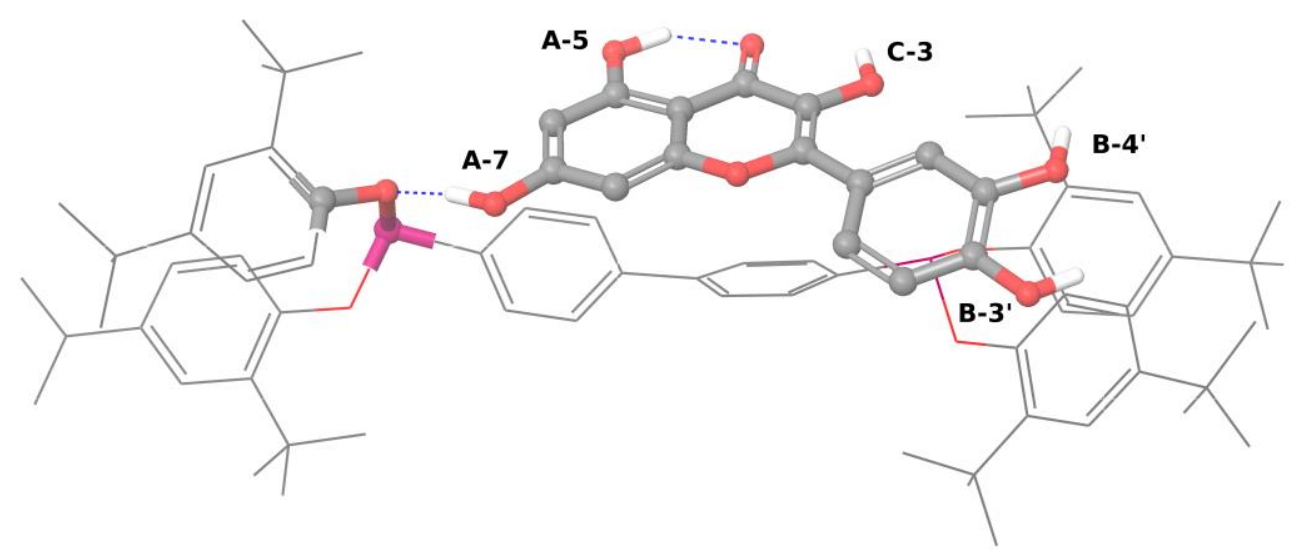

Fig. 10 The most probable configuration of the complex formed through the interaction of quercetin and PEPQ. Thin lines: PEPQ, thick lines: quercetin, and one of the POC groups of PEPQ.

The calculations predicted the development of strong interaction between quercetin and PEPQ. The complex presented in Fig. 10 forms with $96.5 \%$ probability. Besides the formation of hydrogen bonds, also the overlapping of the aromatic rings of the two components contribute to interactions. Interesting and important to note that rings $\mathrm{A}$ and $\mathrm{C}$ participate in the interaction and not the hydroxyl groups taking part in the stabilization reactions. The formed complex explains the changes in the melting temperature of quercetin, the shift in the POC bond of PEPQ as well as the large efficiency of the stabilizer. The development of interactions between rutin and PEPQ leads to a complex structure (Fig. 11), the formation of which has the probability of $99.5 \%$. Only aromatic interactions form between the two molecules and some intramolecular hydrogen bonds within rutin. At larger 
rutin concentrations, sufficient amount of the natural antioxidant is present to protect the polymer against degradation. Since the interactions do not involve the hydroxyl groups located in ring B, they do not affect the efficiency of the natural antioxidants.

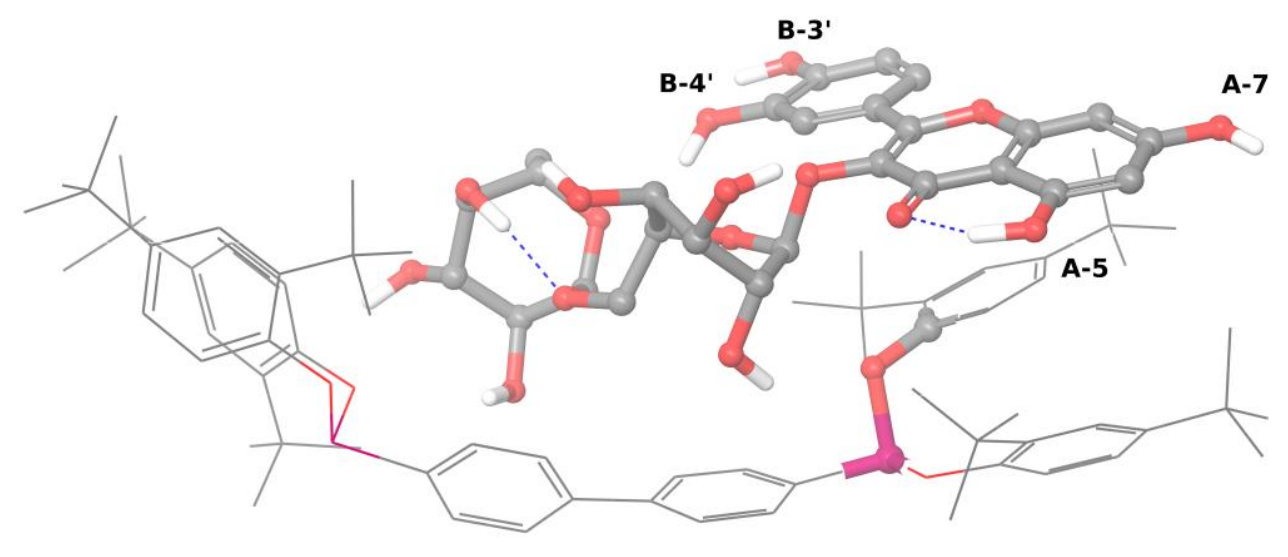

Fig. 11 Complex formed in the interaction of rutin and PEPQ; the formation of intramolecular hydrogen bonds. Thin lines: PEPQ, thick lines: rutin , and one of the POC groups of PEPQ.

\subsection{Discussion}

The main degradation route of the Phillips polyethylene used in this study is the reaction of its chain end double bonds to form long chain branches [32,61]. As Fig. 12 shows, very close correlation exists between the number of vinyl groups and the MFR of the polymer. Viscosity starts to increase below a certain concentration of the vinyl groups, thus the prevention of their reactions is crucial for stabilization. Long chain branches form through the addition of $\mathrm{C}$ centered radicals onto the vinyl group and phenolic antioxidants 
are assumed to react more efficiently with oxygen-centered radicals. On the other hand, phosphite and phosphonite secondary antioxidants are supposed mainly to decompose hydroperoxides and not to react with alkyl radicals. Nevertheless, clear correlation exists between the amount of residual PEPQ and the vinyl group content of the polymer (Fig. 13). Obviously, the secondary antioxidant or the combination of the two stabilizers prevents the formation of long chain branches. The interaction of the two additives, which leaves intact the most important hydroxyl groups in ring B, may also contribute to this effect. Based on the results presented in Figs. 12 and 13, the efficiency of the two natural antioxidants seems to be very similar at least at large additive contents.

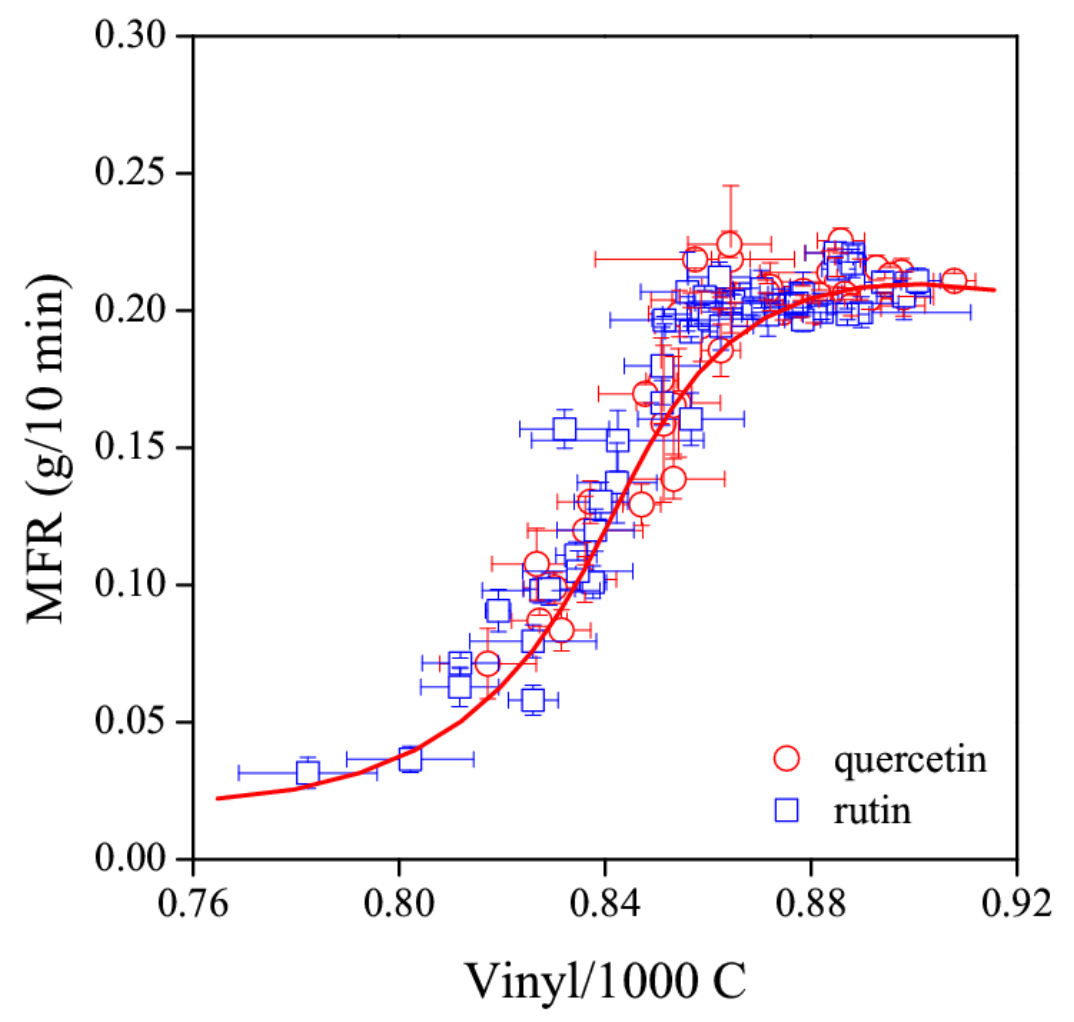

Fig. 12 Correlation between the vinyl content of the polymer and its melt flow rate; effect of the type of the natural antioxidant. Symbols: (O) quercetin, ( $\square$ ) rutin. 


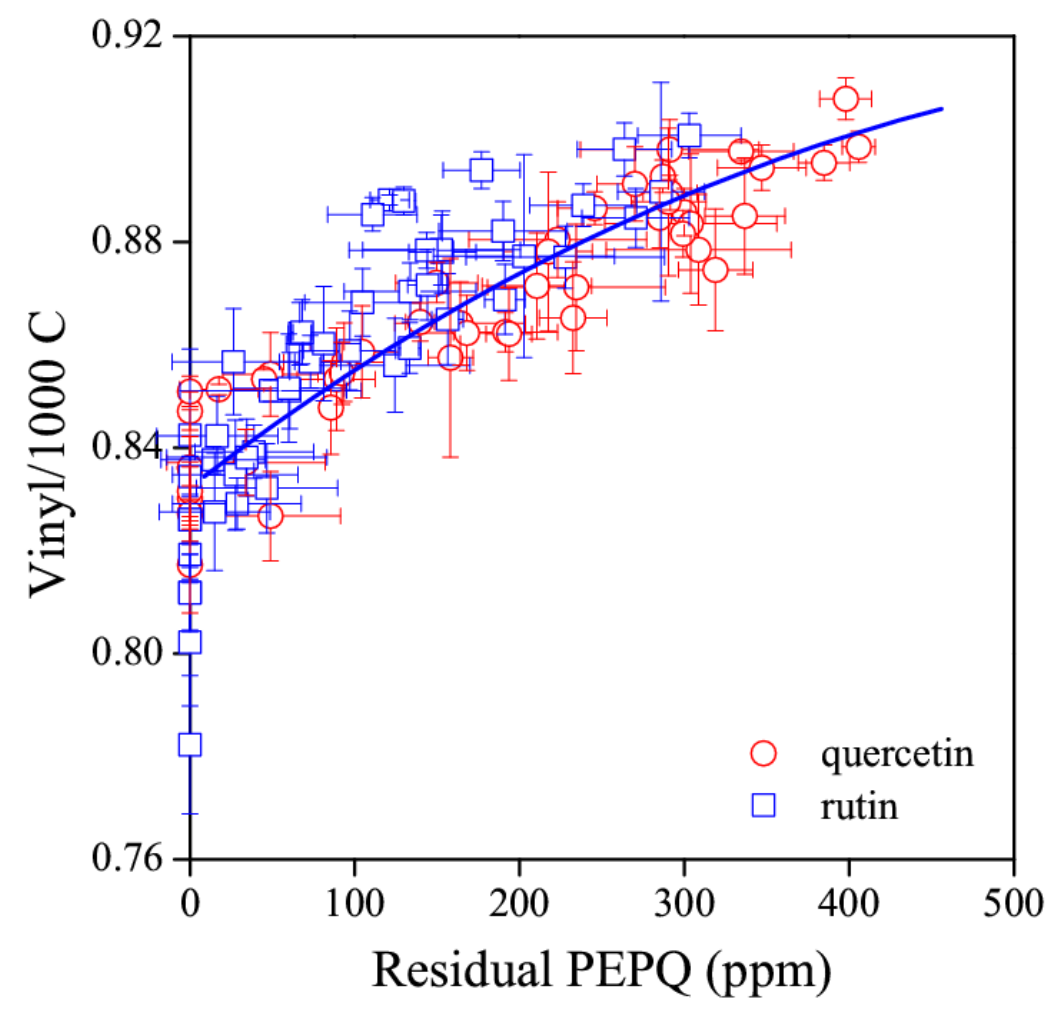

Fig. 13 Dependence of the vinyl concentration of PE on the residual amount of the secondary antioxidant (PEPQ); similar effect of the natural antioxidants studied. Symbols: $(\bigcirc)$ quercetin, $(\square)$ rutin.

One question remained open in this study, the deteriorating effect of rutin at small concentrations. One plausible explanation might be the partial degradation of rutin. Saccharides are sensitive to temperature and the high temperature of processing, $260{ }^{\circ} \mathrm{C}$ in this case, might result in the degradation of the disaccharide substitution. Degradation may involve the entire molecule, or only the saccharide moiety, but the degradation products may also interfere with the stabilization reactions. TGA measurements were carried out in order to check this hypothesis. The sample was heated up to $260^{\circ} \mathrm{C}$ with a rate of $20^{\circ} \mathrm{C} / \mathrm{min}$ and then held there until the end of the run (15 min). The results presented in Fig. 14 clearly 
show the inferior stability of rutin. Consequently, although rutin is as efficient as quercetin at large concentration, its deteriorating effect at small additive contents and limited thermal stability does not make it a good candidate as processing stabilizer for polymers. Nevertheless, the relationship between inferior thermal stability and deteriorating effect at small antioxidant contents needs further study and proof.

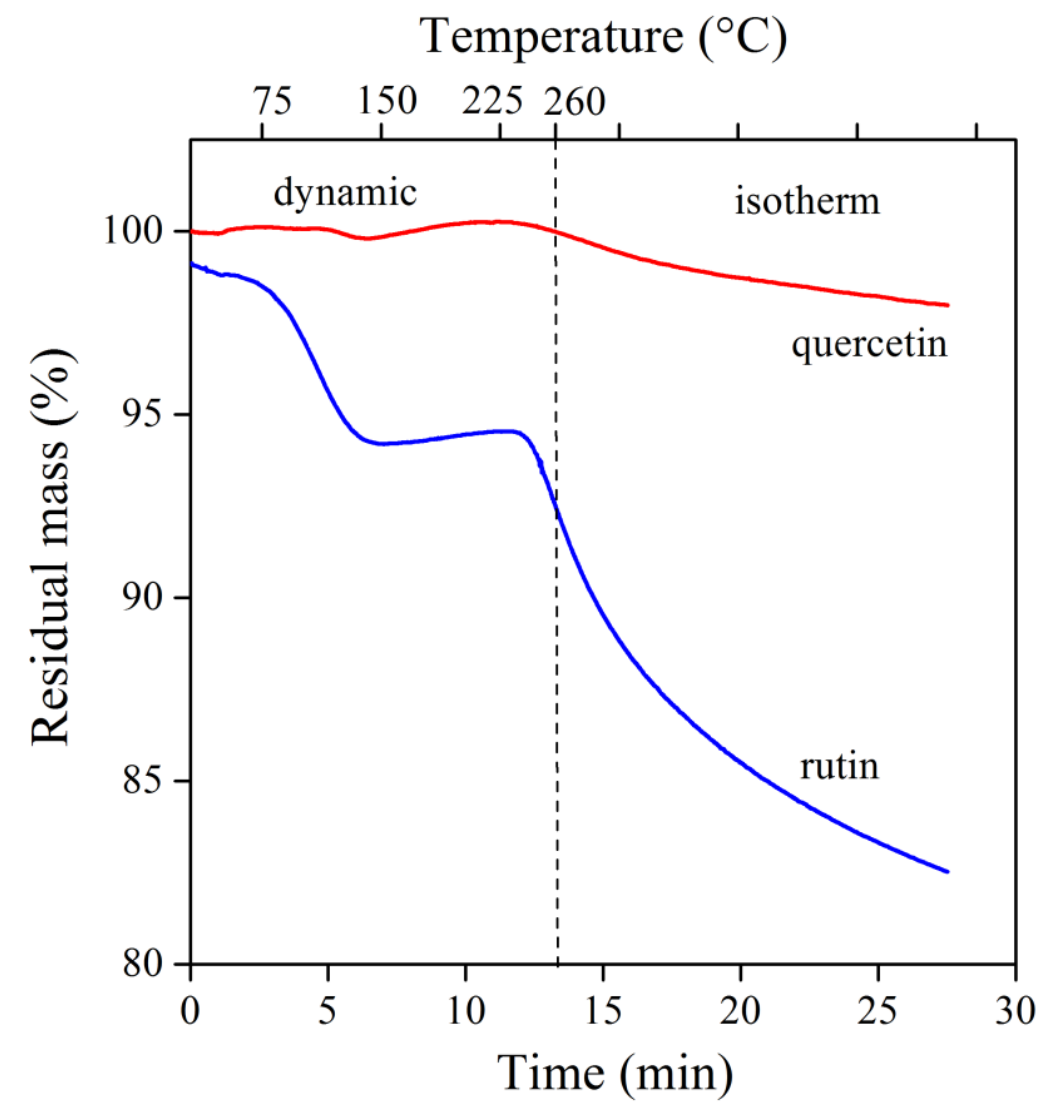

Fig. 14 Thermal stability of the two natural antioxidants studied in TGA measurements simulating processing conditions. Heating rate in the dynamic stage: 20 ${ }^{\circ} \mathrm{C} / \mathrm{min}$; temperature in the isotherm stage: $260^{\circ} \mathrm{C}$.

\section{CONCLUSIONS}

The study of the effect and efficiency of rutin, a flavonoid type natural antioxidant, in the melt stabilization of polyethylene showed that rutin is as efficient melt stabilizer as 
quercetin, the compound used as reference. On the other hand, rutin has a deteriorating effect on the stability of the polymer at small concentrations probably because it partially decomposes at the high temperature of degradation testing and maybe also during processing. The comparison of bond dissociation enthalpies showed that the substitution of the hydroxyl group in ring $\mathrm{C}$ of quercetin by saccharide moieties increases their value, but the small increase does not influence the efficiency of the stabilizer much. This result indicates that bond dissociation enthalpies play a role in stabilization, but other factors also influence efficiency. FTIR and DSC measurements indicated the interaction of the natural antioxidants and the phosphonite secondary stabilizer and the development of interactions was confirmed also by molecular modeling. Hydrogen bonds and aromatic, $\pi$ electron interactions develop between the two types of components, mainly between the hydroxyl groups in ring $\mathrm{A}$, as well as with rings $\mathrm{A}$ and $\mathrm{C}$ thus they do not influence the stabilization efficiency of the antioxidants. The natural antioxidants quercetin [22], dihydromyricetin [23] and curcumin [20-21] are very efficient melt stabilizers, but rutin and silymarin [24] are less advantageous.

\section{ACKNOWLEDGEMENTS}

The National Research Fund of Hungary (OTKA K 120039) is acknowledged for the financial support of the research. One of the authors, BK is grateful for the financial support provided by the ÚNKP-17-3-III New National Excellence Program of the Ministry of Human Capacities. BH and GS gratefully thank for the financial support of the National Research, Development, and Innovation Office (NKFIH, Grant No. KKP126451). 


\section{REFERENCES}

[1] Gol'dberg V M, Zaikov G E. Kinetics of mechanical degradation in melts under model conditions and during processing of polymers - A review. Polym Degrad Stab 1987;19(3):221-250.

[2] Brocca D, Arvin E, Mosbaek H. Identification of organic compounds migrating from polyethylene pipelines into drinking water. Water Res 2002;36(15):36753680.

[3] Pokorny J. Natural antioxidants for food use. Trends Food Sci Technol $1991 ; 2: 223-227$.

[4] Falowo AB, Fayemi PO, Muchenje V. Natural antioxidants against lipid-protein oxidative deterioration in meat and meat products: A review. Food Res Int 2014;64:171-181.

[5] Al-Malaika S, Ashley H, Issenhuth S. The antioxidant role of $\alpha$-tocopherol in polymers. I. The nature of transformation products of $\alpha$-tocopherol formed during melt processing of LDPE. J Polym Sci A-1 1994;32:3099-3113.

[6] Al-Malaika S, Goodwin C, Issenhuth S, Burdick D. The antioxidant role of alphatocopherol in polymers II. Melt stabilising effect in polypropylene. Polym Degrad Stab 1999;64(1):145-156.

[7] Al-Malaika S, Issenhuth S. The antioxidant role of alpha-tocopherol in polymers III. Nature of transformation products during polyolefins extrusion. Polym Degrad Stab 1999;65(1):143-151.

[8] Al-Malaika S, Issenhuth S, Burdick D. The antioxidant role of vitamin E in polymers V. Separation of stereoisomers and characterisation of other oxidation products of DL-alpha-tocopherol formed in polyolefins during melt processing. Polym Degrad Stab 2001;73(3):491-503. 
[9] Delfosse D, Lerf R, Zurbru D, Ag N, Zu E. Use of vitamin E to protect crosslinked UHMWPE from oxidation. Biomaterials 2010;31:3643-3648.

[10] Shen J, Costa L, Xu Y, Cong Y, Cheng Y, Liu X, Fu J. Stabilization of highly crosslinked ultra high molecular weight polyethylene with natural polyphenols. Polym Degrad Stab 2014;105:197-205.

[11] Affatato S, Salvatore J, Mattia D, Bracco P, Pavoni E, Taddei P. Wear performance of neat and vitamin E blended highly cross-linked PE under severe conditions : The combined effect of accelerated ageing and third body particles during wear test. J Mech Behav Biomed Mater, 2016;64:240-252.

[12] Alexy P, Kosikova B, Podstranska G. The effect of blending lignin with polyethylene and polypropylene on physical properties. Polymer 2000;41(13):4901-4908.

[13] Pouteau C, Dole P, Cathala B, Averous L, Boquillon N. Antioxidant properties of lignin in polypropylene. Polym Degrad Stab 2003;81(1):9-18.

[14] Gregorová A, Kosikova B, Moravcik R. Stabilization effect of lignin in natural rubber. Polym Degrad Stab 2006;91(2):229-233.

[15] Shahidi F, Ambigaipalan P. Phenolics and polyphenolics in foods, beverages and spices : Antioxidant activity and health effects. J Functional Foods 2015;18:820897.

[16] Koontz JL, Marcy JE, O'Keefe SF, Duncan SE, Long TE, Moffitt RD. Polymer processing and characterization of LLDPE films loaded with alpha-tocopherol, quercetin, and their cyclodextrin inclusion complexes. J Appl Polym Sci 2010;117(4):2299-2309. 
[17] Samper MD, Fages E, Fenollar O, Boronat T, Balart R. The potential of flavonoids as natural antioxidants and UV light stabilizers for polypropylene. J Appl Polym Sci 2013;129(4):1707-1716.

[18] Xin M, Ma Y, Xu K, Chen M. Dihydromyricetin: An effective non-hindered phenol antioxidant for linear low-density polyethylene stabilisation. J Therm Anal Calorim 2013;114(3):1167-1175.

[19] Xin M, Ma Y, Lin W, Xu K, Chen M. Use of dihydromyricetin as antioxidant for polypropylene stabilization. J Therm Anal Calorim. 2015;120(3):1741-1747.

[20] Tátraaljai D, Kirschweng B, Kovács J, Földes E, Pukánszky B. Processing stabilisation of PE with a natural antioxidant, curcumin. Eur Polym J 2013;49(6):1196-1203.

[21] Tátraaljai D, Kirschweng B, Földes E, Pukánszky B. Efficiency of curcumin, a natural antioxidant, in the processing stabilization of PE: Concentration effects. Polym Degrad Stab 2015;118(8):17-23.

[22] Tátraaljai D, Földes E, Pukánszky B. Efficient melt stabilization of polyethylene with quercetin, a flavonoid type natural antioxidant. Polym Degrad Stab 2014;102(1):41-48.

[23] Kirschweng B, Bencze K, Sárközi M, Hégely B, Samu Gy, Hári J, Tátraaljai D, Földes E, Kállay M, Pukánszky B. Melt stabilization of polyethylene with dihydromyricetin , a natural antioxidant. Polym Degrad Stab 2016;133(11):192200.

[24] Kirschweng B, Vörös B, Tátraaljai D, Zsuga M, Földes E, Pukánszky B. Natural antioxidants as melt stabilizers for PE: Comparison of silymarin and quercetin. Eur Polym J 2017;90(5):456-466. 
[25] Kreft S, Knapp M, Kreft I. Extraction of rutin frombuckwheat (Fagopyrum esculentum Moench) seeds and determination by capillary electrophoresis. J Agric Food Chem 1997;47(11):4649-4652.

[26] Ganeshpurkar A, Saluja AK. The pharmacological potential of rutin. Saudi Pharm J 2017;25(2):149-164.

[27] Machado DG, Bettio LE, Cunha MP, Santos AR, Pizzolatti MG, Brighente IM, Rodrigues AL. Antidepressant-like effect of rutin isolated from the ethanolic extract from Schinusmolle L. in mice: evidence for the involvement of the serotonergicand noradrenergic systems. Eur J Pharmacol 2008;587(1-3):163-168.

[28] Wang SW, Wang YJ, Su YJ, Zhou WW, Yang SG, Zhang R, Zhao M, Li YN, Zhang ZP, Zhan DW, Liu RT. Rutin inhibits beta-amyloid aggregation and cytotoxicity, attenuatesoxidative stress, and decreases the production of nitric oxide and proinflammatory cytokines. Neurotoxicology 2012;33(3):482-490.

[29] Ortolani O, Caggiano M, Mannelli R, Gogliettino A, Tufano R. Protection from ischemia-reperfusion damage in patients with stroke: the role of rutin and GSH. Transplant Proc 1995;27(5):2877-2878.

[30] Trouillas P, Marsal P, Siri D, Lazzaroni R, Duroux JL. A DFT study of the reactivity of $\mathrm{OH}$ groups in quercetin and taxifolin antioxidants: The specificity of the 3-OH site. Food Chem 2006;97:679-688.

[31] Osorio E, Perez EG, Areche C, Ruiz LM, Cassels BK, Florez E, Tiznado W. Why is quercetin a better antioxidant than taxifolin? Theoretical study of mechanisms involving activated forms. J Mol Model 2013;19(5):2165-2172.

[32] Moss S, Zweifel H. Degradation and stabilization of high density polyethylene during multiple extrusions. Polym Degrad Stab 1989;25:217-245. 
[33] Klemchuk PP, Horng PL. Transformation products of hindered phenolic antioxidants and colour developments in Polyolefins. Polym Degrad Stab 1991;34:333-346.

[34] Breese KD, Lamethe JF, DeAmitt C. Improving synthetic hindered phenol antioxidants: learning from vitamin E. Polym Degrad Stab 2000;70:89-96.

[35] Jovanovic SV, Steenken S, Tosic M, Marjanovic B, Simic MG. Flavonoids as Antioxidants. J Am Chem Soc 1994;116:4846-4851.

[36] Jovanovic SV, Steenken S, Hara Y, Simic MG. Reduction potentials of flavonoid and model phenoxyl radicals. Which ring in flavonoids is responsible for antioxidant activity? J Chem Soc Perkin Trans 2 1996;2:2497-2504.

[37] Litwinienko G, Ingold KU. Abnormal solvent effects on hydrogen atom abstraction. 1. The reactions of phenols with 2,2-diphenyl-1-picrylhydrazyl (dpph*) in alcohols. J Org Chem 2003;68(9):3433-3438.

[38] Zhang HY, Ji HF. How vitamin E scavenges DPPH radicals in polar protic media. New J Chem 2006;30:503-504.

[39] Anouar E, Kosinova P, Kozlowski D, Mokrini R, Duroux JL, Trouillas P. New aspects of the antioxidant properties of phenolic acids: a combined theoretical and experimental approach. Phys Chem Chem Phys 2009;11:7659-7668.

[40] Burton GW, Doba T, Gabe EJ, Hughes L, Lee FL, Prasad L, Ingold KU. Autooxidation of biological molecules. 4. Maximizing the antioxidant activity of phenols. J Am Chem Soc 1985;107:7053-7065.

[41] de Heer MI, Mulder P, Korth HG, Ingold KU, Lusztyk J. Hydrogen atom abstraction kinetics from intramolecularly hydrogen bonded ubiquinol-0 and other (poly)methoxy phenols. J Am Chem Soc 2000;122:2355-2360. 
[42] Pospíšil J. Chemical and photochemical behaviour of phenolic antioxidants in polymer stabilization: a state of the art report, part II. Polym Degrad Stab 1993;39:103-115.

[43] Pospíśil J. Chemical and photochemical behaviour of phenolic antioxidants in polymer stabilization: a state of the art report, Part I. Polym Degrad Stab 1993;40:217-132.

[44] Kirschweng B, Tátraaljai D, Földes E, Pukánszky B. Natural antioxidants as stabilizers for polymers. Polym Degrad Stab 2017;145(11):25-40.

[45] Cai W, Chen Y, Xie L, Zhang H, Hou C. Characterization and density functional theory study of the antioxidant activity of quercetin and its sugar-containing analogues. Eur Food Res Technol 2014;238:121-128.

[46] Anbazhagan V, Kalaiselvan A, Jaccob M, Venuvanalingam P, Renganathan R. Investigations on the fluorescence quenching of 2,3-diazabicyclo[2.2.2]oct-2-ene by certain flavonoids. J Photochem Photobio B 2008;91:143-150.

[47] Foti MC, Daquino C, DiLabio GA, Ingold KU. Kinetics of the oxidation of quercetin by 2,2-diphenyl-1-picrylhydrazyl (DPPH'). Org Lett 2011;13(18):48264829.

[48] Amic A, Lucic B, Stepanic V, Markovic Z, Markovic S, Markovic JMD, Amic D. Free radical scavenging potency of quercetin catecholic colonic metabolites: Thermodynamics of $2 \mathrm{H}^{*} / 2 \mathrm{e}$ - processes. Food Chem 2017;218:144-151.

[49] Savic S, Vojinovic K, Milenkovic S, Smelcerovic A, Lamshoeft M, Petronijevic Z. Enzymatic oxidation of rutin by horseradish peroxidase: Kinetic mechanism and identification of a dimeric product by LC-Orbitrap mass spectrometry. Food Chem 2013;141:4194-4199. 
[50] Perdew JP, Burke K, Ernzerhof M. Generalized gradient approximation made simple. Phys Rev Lett 1996;77:3865.

[51] Rolik Z, Szegedy L, Ladjánszki I, Ladóczki B, Kállay M. MRCC, a quantum chemical program suite. J Chem Phys 2013;139:094105, as well as: www.mrcc.hu.

[52] Grimme S, Antony J, Ehrlich S, Krieg H. A consistent and accurate ab initio parametrization of density functional dispersion correction (DFT-D) for the 94 elements H-Pu. J Chem Phys 2010;132:154104.

[53] Grimme S, Ehrlich S, Goerigk L. Effect of the damping function in dispersion corrected density functional theory. J Comput Chem 2011;32(7):1456.

[54] Halgren TA. Merck molecular force field. I. Basis, form, scope, parameterization, and performance of MMFF94. J Comput Chem 1996;17(5-6):490-519.

[55] Marvin was used for drawing, displaying and characterizing chemical structures, substructures and reactions, Marvin 17.8.0, 2017, ChemAxon (http://www.chemaxon.com)

[56] MOPAC2016, James J. P. Stewart, Stewart Computational Chemistry, Colorado Springs, CO, USA, HTTP://OpenMOPAC.net (2016)

[57] Stewart JJP. Optimization of Parameters for Semiempirical Methods V: Modification of NDDO Approximations and Application to 70 Elements. J Mol Modeling 2007;13(12):1173-1213.

[58] ̌ezáč J, Hobza P. Advanced Corrections of Hydrogen Bonding and Dispersion for Semiempirical Quantum Mechanical Methods. J Chem Theory Comput 2012;8(1):141-151.

[59] Schrödinger Release 2017-1: Maestro, Schrödinger, LLC, New York, NY, 2017. 
[60] Boys SF, Bernardi F. Calculation of Small Molecular Interactions by Differences of Separate Total Energies - Some Procedures with Reduced Errors. Mol Phys 1970;19:553.

[61] Epacher E, Fekete E, Gahleitner M, Pukánszky B. Chemical reactions during the processing of stabilized PE: 2. Structure/property correlations. Polym Degrad Stab $1999 ; 63(3): 499-507$. 